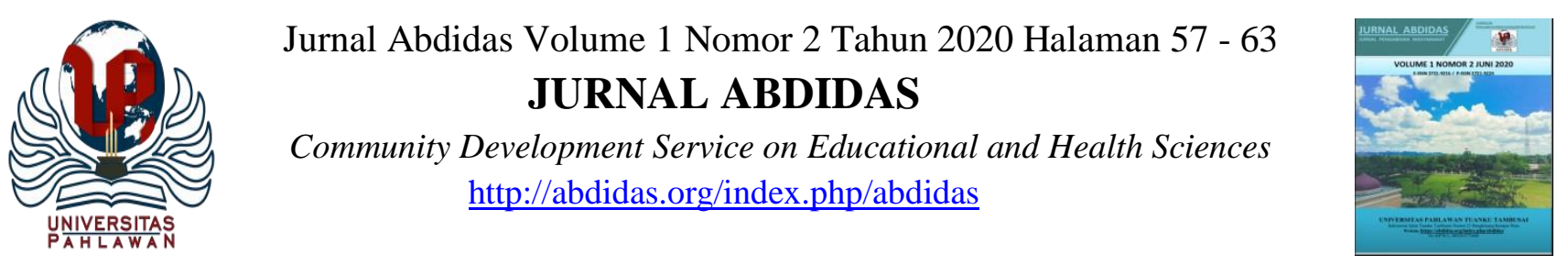

\title{
EFEKTIVITAS JUS MENTIMUN TERHADAP PENURUNAN TEKANAN DARAH PADA LANSIA PENDERITA HIPERTENSI DI DESA KONDANGJAYA PANDEGLANG - BANTEN
}

\author{
Ucu Wandi Somantri ${ }^{1}$ \\ Prodi Kesehatan Masyarakat, Fakultas Sains, Farmasi dan Kesehatan, Universitas Mathla'ul Anwar ${ }^{1}$ \\ E-Mail : ucuancayur@gmail.com ${ }^{1}$
}

\begin{abstract}
Abstrak
Hipertensi adalah salah satu gejala peningkatan tekanan darah yang kemudian mempengaruhi kerangka kerja organ lain, seperti stroke untuk otak atau penyakit jantung koroner. Penyakit ini yakni salah satu masalah utama di bidang kesehatan masyarakat di Indonesia maupun di dunia. Data WHO pada tahun 2015 menuangkan bahwa kurang lebih 1,13 miliar orang di dunia menderita hipertensi, artinya 1 dari 3 orang di dunia didiagnosis menderita hipertensi. Kegiatan pengabdian masyarakat ini diikuti oleh 12 orang pasien Hipertensi, laki-laki dan perempuan. Kegiatan ini dilaksanakan dalam 7 hari. Hari ke-1 dibagi menjadi tiga sesi yakni penyuluhan, demonstrasi, pengukuran tekanan darah. Dalam penyuluhan, warga diinformasikan tentang definisi, tanda, cara pencegahan, cara penanganan hipertensi. Demonstrasi dengan cara desain quasi eksperimen pre and post test with control group. Dengan memberikan perlakuan pada kelompok intervensi dengan pemberian jus mentimun dan kelompok kontrol tidak diberikan jus mentimun, hari ke-2 hingga ke-6 pada pasien intervensi diintruksikan untuk meminum jus mentimun 2x dalam sehari, waktunya yaitu pagi jam 08.00 WIB, malam jam 20.00 WIB dan pada pasien kontrol tidak diperkenankan meminum jus mentimun dan diperiksa tekanan darah setiap hari. Pada hari terakhir melakukan pemeriksaan tekanan darah dan mengevaluasi hasil kegiatan yang telah dilakukan. Hasil pengabdian masyarakat diketahui berdasarkan presentase rata-rata pada pasien intervensi hari pertama sampai dengan hari ke tujuh mengalami penurunan yang sangat signifikan yaitu 154,4/85,7 $\mathrm{mmHg}$, sedangkan pada pasien kontrol hari pertama sampai dengan hari ke tujuh tidak mengalami penurunan sebesar 168/90,4 mmHg.
\end{abstract}

Kata kunci: telenursing, hipertensi, jus mentimun

\begin{abstract}
Hypertension is one of the symptoms of increased blood pressure which then affects the framework of other organs, such as stroke for the brain or coronary heart disease. This disease is one of the main problems in the field of public health in Indonesia and in the world. The WHO Data in 2015 poured that more or less 1.13 billion people in the world suffer from hypertension, meaning that 1 in 3 people in the world are diagnosed with hypertension. The community service activities were attended by 12 hypertension patients, male and female. This activity is carried out within 7 days. Day 1 is divided into three sessions, namely counseling, demonstration, measurement of blood pressure. In counseling, citizens are informed about definitions, signs, precautions, how to handle hypertension. Demonstration by means of the design quasi experiment pre and post test with control group. By giving treatment in the intervention group with the feeding of cucumber juice and control group is not given the cucumber juice, day 2-6 in patients intervention in the instruction to drink cucumber juice $2 x$ in a day, the time is morning at 08.00 WIB, night at 20.00 WIB and in control patients should not drink juice cucumber and check blood pressure every day. On the last day of blood pressure screening and evaluate the results of activities that have been done. The results of public devotion are known based on the average percentage of intervening patients in the first day until the 7th day experienced a very significant decline, namely 154,4/85,7 mmHg, while in patients first day control until day 7 did not decline by 168/90,4 $\mathrm{mmHg}$.
\end{abstract}

Keywords: telenursing, hypertension, cucumber juice.

Copyright (c) 2020 Ucu Wandi Somantrii

$\triangle$ Corresponding author :

Address : Universitas Mathla'ul Anwar

Email : ucuancayur@gmail.com

ISSN 2721-9224 (Media Cetak)

Phone :

ISSN 2721-9216 (Media Online)

DOI: https://doi.org/10.31004/abdidas.v1i2.14 
58 Efektivitas Jus Mentimun Terhadap Penurunan Tekanan Darah pada Lansia Penderita Hipertensi di Desa Kondangjaya Pandeglang - Banten-Ucu Wandi Somantri

DOI: https://doi.org/10.31004/abdidas.v1i2.14

\section{PENDAHULUAN}

Hipertensi adalah salah satu gejala peningkatan tekanan darah yang kemudian mempengaruhi kerangka kerja organ lain, seperti stroke untuk otak atau penyakit jantung koroner untuk pembuluh darah untuk pembuluh darah jantung dan otot jantung. Penyakit ini yakni salah satu masalah utama di bidang kesehatan masyarakat di Indonesia maupun di dunia. Data dari Organisasi Kesehatan Dunia (WHO) pada tahun 2015 menuangkan bahwa kurang lebih 1,13 miliar orang di dunia menderita hipertensi, artinya 1 dari 3 orang di dunia didiagnosis menderita hipertensi. Besaran orang atas hipertensi terusmenerus meningkat setiap tahun, diperkirakan pada tahun 2025 akan ada 1,5 miliar orang yang terjangkit hipertensi, dan diperkirakan setiap tahun 10,44 juta orang meninggal karena hipertensi dan komplikasinya (Salman et al., 2015).

Data dari Riset Kesehatan Dasar 2018 menyatakan prevalensi tekanan darah tinggi berdasarkan hasil pengukuran pada populasi berusia 18 tahun sebesar 34,1\%, tertinggi di Kalimantan Selatan (44,1\%), sedangkan yang terendah di Papua adalah (22,2\%). Diperkirakan jumlah kejadian tekanan darah tinggi di Indonesia kurang lebih 63.309.620 orang, sedangkan mortalitas di Indonesia dampak tekanan darah tinggi sekitar 427.218 mortalitas (Salman et al., 2015).

Tekanan darah tinggi timbul pada kelompok usia 31-44 tahun (31,6\%), usia 45-54 tahun (45,3\%), sedangkan pada usia 55-64 tahun $(55,2 \%)$. Dari angka kejadian tekanan darah tinggi sejumlah $34,1 \%$ diketahui maka sejumlah $8,8 \%$ terdiagnosis tekanan darah tinggi dan 13,3\% orang yang terdiagnosis hipertensi tidak minum obat serta $32,3 \%$ tidak rutin minum obat. Kejadian ini menunjukkan maka beberapa besar pada penderita tekanan darah tinggi tidak mengetahui bahwa dirinya mengalami tekanan darah tinggi sehingga tidak memperoleh pengobatan apapun.

Organisasi Kesehatan Dunia (WHO) mengklasifikasikan hipertensi berdasarkan usia di bawah tiga kriteria, yaitu :

1. Kelompok usia 20-29 tahun, tekanan darah sistole $140 \mathrm{mmHg}$ / diastole $90 \mathrm{mmHg}$

2. Kelompok usia 30-64 tahun, tekanan darah sistole $160 \mathrm{mmHg}$ / diastole $95 \mathrm{mmHg}$

3. Kelompok usia 65 tahun, tekanan darah sistole $170 \mathrm{mmHg} /$ diastole $95 \mathrm{mmHg}$.

Di bawah ini adalah kategori tekanan darah yang dikemukakan oleh Kementerian Kesehatan Republik Indonesia (Sumiati, 2017).

Berikut adalah klasifikasi tekanan darah sebagai berikut :

Tabel . 1. Klasifikasi Hipertensi

\begin{tabular}{lcc}
\hline \multicolumn{1}{c}{ Kategori } & $\begin{array}{c}\text { Tekanan Darah } \\
\text { Sistolik } \\
(\mathbf{m m H g})\end{array}$ & $\begin{array}{c}\text { Tekanan } \\
\text { Darah } \\
\text { Diastolik } \\
(\mathbf{m m H g})\end{array}$ \\
\hline Normal & $120-129$ & $80-89$ \\
Normal tinggi & $130-139$ & 89 \\
$\begin{array}{l}\text { Hipertensi } \\
\text { Stage 1 }\end{array}$ & $140-159$ & $90-99$ \\
$\begin{array}{l}\text { Hipertensi } \\
\text { Stage 2 }\end{array}$ & $\geq 160$ & $\geq 100$ \\
$\begin{array}{l}\text { Hipertensi } \\
\begin{array}{l}\text { Stage 3 } \\
\text { Butuh } \\
\text { Perawatan } \\
\text { Segera }\end{array}\end{array}$ & $\geq 180$ & $\geq 110$ \\
\hline
\end{tabular}


59 Efektivitas Jus Mentimun Terhadap Penurunan Tekanan Darah pada Lansia Penderita Hipertensi di Desa Kondangjaya Pandeglang - Banten-Ucu Wandi Somantri

DOI: https://doi.org/10.31004/abdidas.v1i2.14

Terdapat dua pengobatan yang dilakukan guna menyembuhkan tekanan darah tinggi, yaitu terapi farmakologis dan terapi non farmakologis. Terapi farmakologis merupakan dengan memakai obat antihipertensi yang terbukti mengurangi tekanan darah, sedangkan terapi non-farmakologis atau juga disebut modifikasi gaya hidup yang meliputi berhenti merokok, mengurangi kelebihan berat badan, menghindari alkohol, memodifikasi diet dan termasuk psikis termasuk mengurangi stres, olahraga, dan istirahat (Etri Yanti, Niken, 2018).

Salah satu pengobatan non-farmakologis yang bisa diberikan untuk penderita tekanan darah tinggi adalah pengobatan nutrisi yang dilakukan menggunakan pengelolaan diet tekanan darah tinggi. Misalnya dengan membatasi konsumsi garam, mempertahankan asupan kalium, kalsium, dan magnesium dan membatasi asupan kalori jika berat badan bertambah. DASH (Dietary Approaches to Stop Hypertension) menganjurkan bahwa pada penderita tekanan darah tinggi/ hipertensi mengkonsumsi banyak buah dan sayuran, meningkatkan konsumsi serat, dan minum banyak air. Pengobatan diet ialah alternatif yang baik untuk penderita tekanan darah tinggi/ hipertensi. Pengobatan ini dapat dilakukan melalui mengonsumsi sayuran yang dapat memengaruhi tekanan darah, seperti mentimun (cucumis sativus) (Ismalia et al., 2016).

Dengan pemberian jus mentimun (cucumis sativus) sangat cukup berpengaruh ketika menurunkan tekanan darah atas pengidap tekanan darah tinggi/ hipertensi, sehingga diharapkan pegawai kesehatan terutama perawat kian aktif ketika memberikan penyuluhan tentang pendayagunaan mentimun tentang penurunan tekanan darah pada penderita tekanan darah tinggi/ hipertensi kepada masyarakat terutama pada penderita hipertensi. (Etri Yanti, Niken, 2018).

\section{METODE}

Intervensi

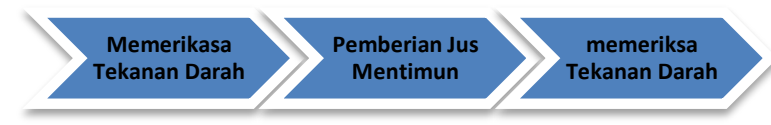

Kontrol

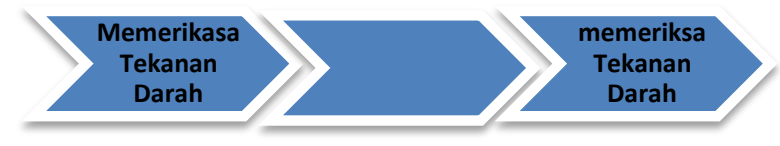

Bagan 1. Gambaran Perlakuan Kelompok Intervensi dan Kelompok Kontrol

Kegiatan dilakukan di Desa Kondangjaya, Kecamatan Cisata, Kabupaten Pandeglang, dari tanggal 10-17 Agustus 2019. Kegiatan ini diikuti oleh 12 orang pasien hipertensi, laki-laki dan perempuan. Kegiatan ini dilaksanakan dalam 7 hari. Hari ke-1 dibagi menjadi tiga sesi yakni penyuluhan, demonstrasi, pengukuran tekanan darah. Dalam penyuluhan, warga diinformasikan tentang definisi, tanda, cara pencegahan, cara penanganan hipertensi. Demonstrasi dengan cara desain quasi eksperimen pre and post test with control group. Dengan memberikan perlakuan pada kelompok intervensi dengan pemberian jus mentimun dan kelompok kontrol, skema penelitian dapat dilihat pada bagan 1. Hari ke 2-6 pada pasien intervensi diintruksikan untuk meminum jus mentimun 2x dalam sehari, waktunya yaitu pagi jam 08.00 WIB, malam jam 20.00 WIB dan pada pasien kontrol tidak diperkenankan meminum jus 
60 Efektivitas Jus Mentimun Terhadap Penurunan Tekanan Darah pada Lansia Penderita Hipertensi di Desa Kondangjaya Pandeglang - Banten-Ucu Wandi Somantri

DOI: https://doi.org/10.31004/abdidas.v1i2.14

mentimun dan diperiksa tekanan darah setiap hari bagi pasien intervensi dan kontrol. Pada hari terakhir melakukan pemeriksaan tekanan darah dan mengevaluasi hasil kegiatan yang telah dilakukan.

\section{HASIL DAN PEMBAHASAN}

Kegiatan pengabdian masyarakat ini dilakukan Tim Pengabdi dan dibantu oleh istri kepala Desa Kondangjaya dan ibu-ibu kader. Dilaksanakan di Desa Kondangjaya, Kabupaten Pandeglang, Provinsi Banten. Kegiatan ini diikuti oleh 30 lansia, tetapi hanya 12 yang dijadikan sampel quasi eksperimen pre and post test with control group Hal tersebut dilakukan agar masyarakat memiliki derajat kesehatan yang tinggi. Khususnya untuk mencegah hipertensi pada lansia. Untuk pengukuran quasi eksperimen pre and post test with control group analisisnya sebagai berikut :

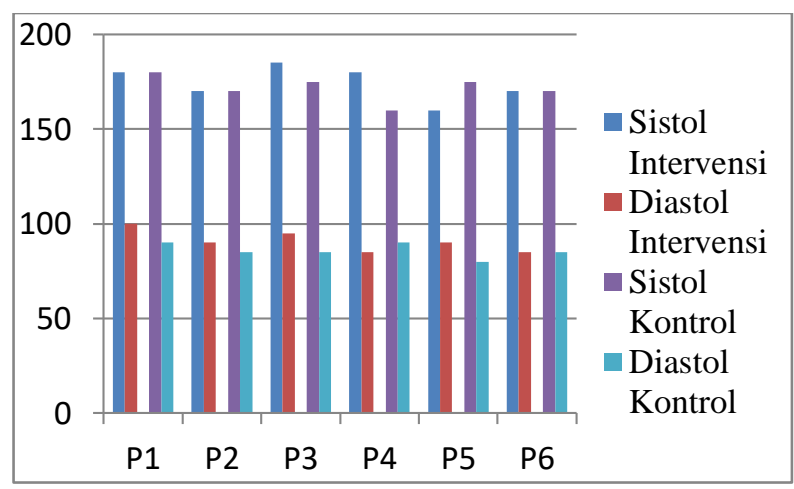

Grafik 1. Pengukuran tekanan darah hari pertama

Grafik 1: hari pertama pengukuran tekanan darah pada 6 orang kelompok intervensi dan 6 orang kelompok kontrol rata-rata pada kelompok intervensi tekanan darah sistole $174,1 \mathrm{mmHg}$ dan tekanan diastole $90,83 \mathrm{mmHg}$ dan rata-rata pada kelompok kontrol tekanan darah sistole 171,66
mmHg dan kelompok kontrol tekanan darah diastole $85,8 \mathrm{mmHg}$.

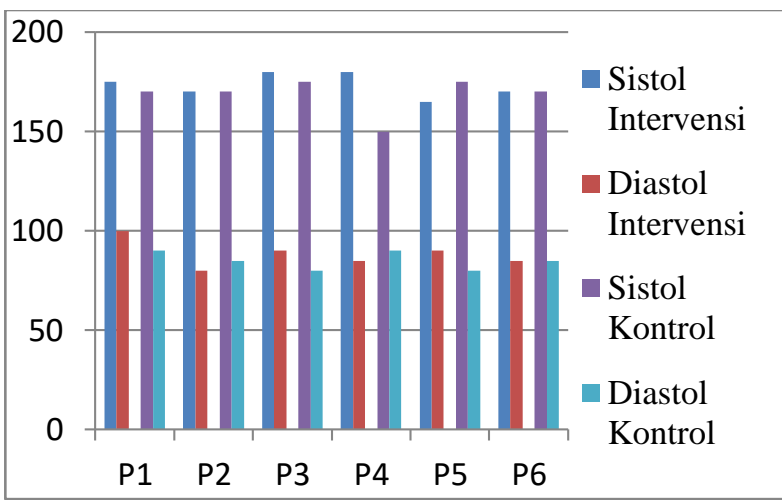

Grafik 2. Pengukuran tekanan darah hari kedua

Grafik 2: hari kedua pengukuran tekanan darah pada 6 orang kelompok intervensi dan 6 orang kelompok kontrol rata-rata pada kelompok intervensi, tekanan darah sistole 173,3 mmHg dan tekanan diastole $88,83 \mathrm{mmHg}$ dan rata-rata pada kelompok kontrol tekanan darah sistole 168,33 mmHg dan kelompok kontrol tekanan darah diastole $85 \mathrm{mmHg}$.

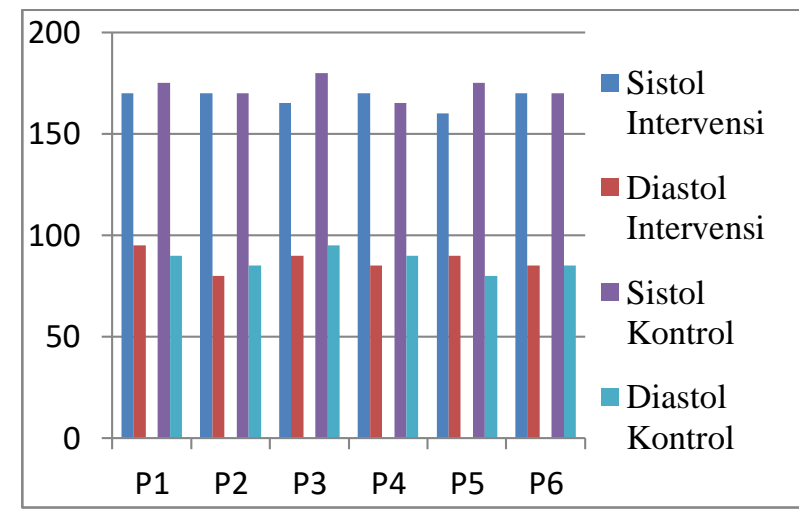

Grafik 3. Pengukuran tekanan darah hari ketiga

Grafik 3: hari ketiga pengukuran tekanan darah pada 6 orang kelompok intervensi dan 6 orang kelompok kontrol rata-rata pada kelompok intervensi, tekanan darah sistole $167,5 \mathrm{mmHg}$ dan tekanan diastole $87,5 \mathrm{mmHg}$ dan rata-rata pada 
61 Efektivitas Jus Mentimun Terhadap Penurunan Tekanan Darah pada Lansia Penderita Hipertensi di Desa Kondangjaya Pandeglang - Banten-Ucu Wandi Somantri

DOI: https://doi.org/10.31004/abdidas.v1i2.14

kelompok kontrol tekanan darah sistole 172,5 mmHg dan kelompok kontrol tekanan darah diastole $87,5 \mathrm{mmHg}$.

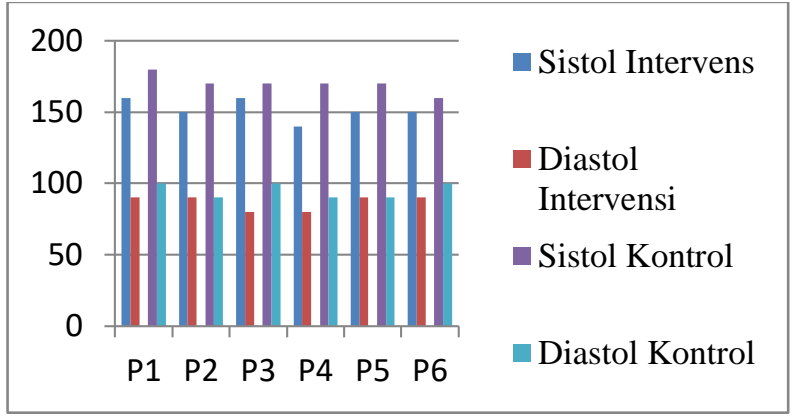

Grafik 4. Pengukuran tekanan darah hari keempat

Grafik 4: hari keempat pengukuran tekanan darah pada 6 orang kelompok intervensi dan 6 orang kelompok kontrol rata-rata pada kelompok intervensi tekanan darah sistole $151,67 \mathrm{mmHg} /$ tekanan diastole $86,7 \mathrm{mmHg}$ dan rata-rata pada kelompok kontrol tekanan darah sistole 170 $\mathrm{mmHg}$ / tekanan diastole $95 \mathrm{mmHg}$.

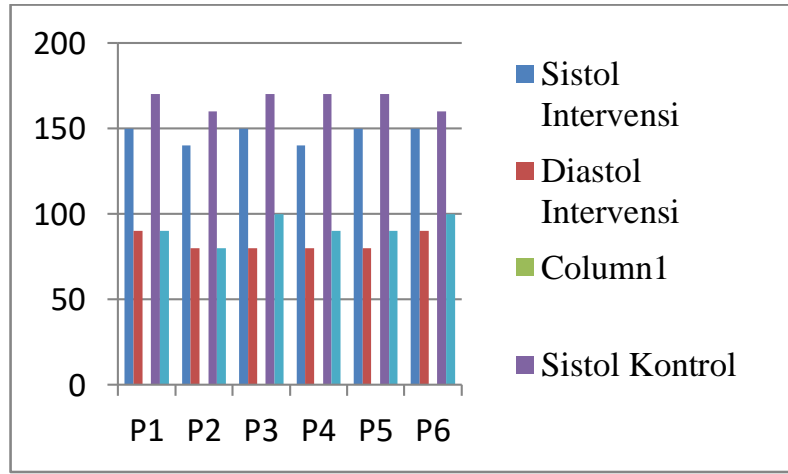

Grafik 5. Pengukuran tekanan darah hari kelima

Grafik 5: hari kelima pengukuran tekanan darah pada 6 orang kelompok intervensi dan 6 orang kelompok kontrol rata-rata pada kelompok intervensi tekanan darah sistole 146,7 $\mathrm{mmHg}$ / tekanan diastole $83,3 \mathrm{mmHg}$ dan rata-rata pada kelompok kontrol tekanan darah sistole 166,6 $\mathrm{mmHg}$ / tekanan diastole $91,7 \mathrm{mmHg}$.

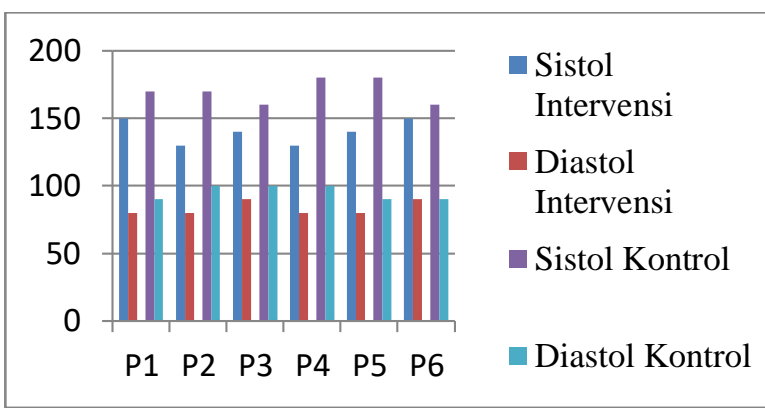

Grafik 6. Pengukuran tekanan darah hari keenam

Grafik 6: hari keenam pengukuran tekanan darah pada 6 orang kelompok intervensi dan 6 orang kelompok kontrol rata-rata pada kelompok intervensi tekanan darah sistole $140 \mathrm{mmHg} /$ tekanan diastole $83,3 \mathrm{mmHg}$ dan rata-rata pada kelompok kontrol tekanan darah sistole 170 $\mathrm{mmHg} /$ tekanan diastole $95 \mathrm{mmHg}$

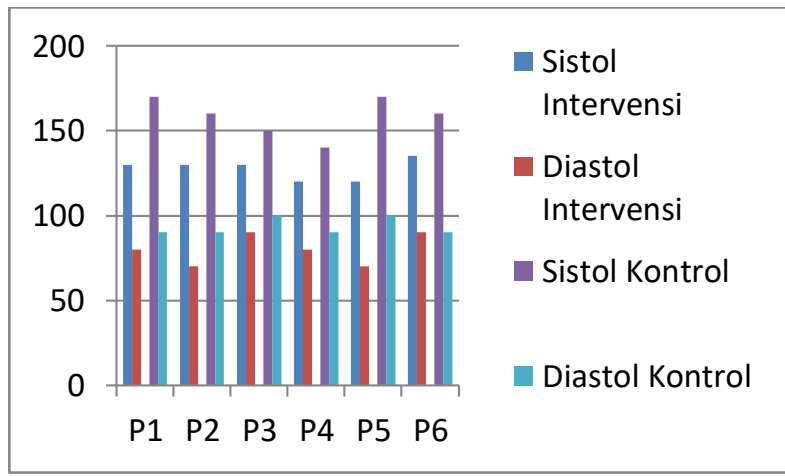

Grafik 7. Pengukuran tekanan darah hari ketujuh

Grafik 7: hari ketujuh pengukuran tekanan darah pada 6 orang kelompok intervensi dan 6 orang kelompok kontrol rata-rata pada kelompok intervensi tekanan darah sistole $127,5 \mathrm{mmHg} /$ tekanan diastole $80 \mathrm{mmHg}$ dan rata-rata pada kelompok kontrol tekanan darah sistole 158,3 $\mathrm{mmHg} /$ tekanan diastole 93,3 $\mathrm{mmHg}$.

Berdasarkan presentase rata-rata pada pasien intervensi hari pertama sampai dengan hari ke 7 (hari ke-1: 174,1 mmHg/ 90,83 mmHg, hari ke-2: 173,3 mmHg/ 88,83 mmHg, hari ke-3: 167,5 
62 Efektivitas Jus Mentimun Terhadap Penurunan Tekanan Darah pada Lansia Penderita Hipertensi di Desa Kondangjaya Pandeglang - Banten-Ucu Wandi Somantri

DOI: https://doi.org/10.31004/abdidas.v1i2.14

$\mathrm{mmHg}$ / 87,5 mmHg, hari ke-4: 151,67 mmHg/ 86,7 mmHg, hari ke-5: 146,7 mmHg/ 83,3 mmHg, hari ke-6: $140 \mathrm{mmHg} / 83,3 \mathrm{mmHg}$, hari ke-7: 127,5 mmHg/80) mengalami penurunan yang sangat signifikan, sedangkan pada pasien kontrol hari pertama sampai dengan hari ke-7 (hari ke-1: $171.66 \mathrm{mmHg} / 85,8 \mathrm{mmHg}$, hari ke-2: 168,33 $\mathrm{mmHg} / 85 \mathrm{mmHg}$, hari ke-3: 172,5 mmHg/ 87,5 $\mathrm{mmHg}$, hari ke-4: $170 \mathrm{mmHg} / 95 \mathrm{mmHg}$, hari ke5: $166,6 \mathrm{mmHg} / 91,7 \mathrm{mmHg}$, hari ke-6: 170 $\mathrm{mmHg} / 95 \mathrm{mmHg}$, hari ke-7: 158,3 mmHg/ 93,3 $\mathrm{mmHg}$ ) tidak mengalami penurunan.

Berdasarkan hasil perlakuan selama 7 hari terhadap 12 responden yaitu 6 responden kelompok kontrol dan 6 responden kelompok intervensi pada pasien yang mengalami gangguan sistem kardiovaskuler atau jantung: hipertensi/ tekanan darah tinggi didapatkan data berikut :

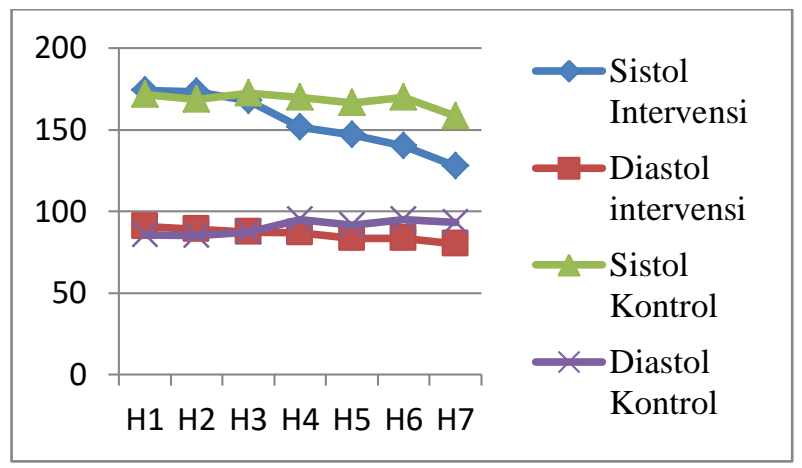

Grafik 8. Hasil intervensi selama 7 hari

Rata-rata pada kelompok intervensi dengan pemberian jus mentimun diperoleh rata-rata 154,4 $\mathrm{mmHg} / 85,7 \mathrm{mmHg}$ sedangkan pada kelompok kontrol didapatkan rata-rata $168 \mathrm{mmHg} / 90,4$ mmHg. Jus mentimun bisa menurunkan tekanan darah dengan aturan minum $2 \mathrm{x}$ dalam sehari dengan waktu pemberian pagi dan sore, sedangkan jumlah yang diminumkan dalam 1 kali pemberian yaitu 1 gelas kurang lebih $250 \mathrm{cc}$.
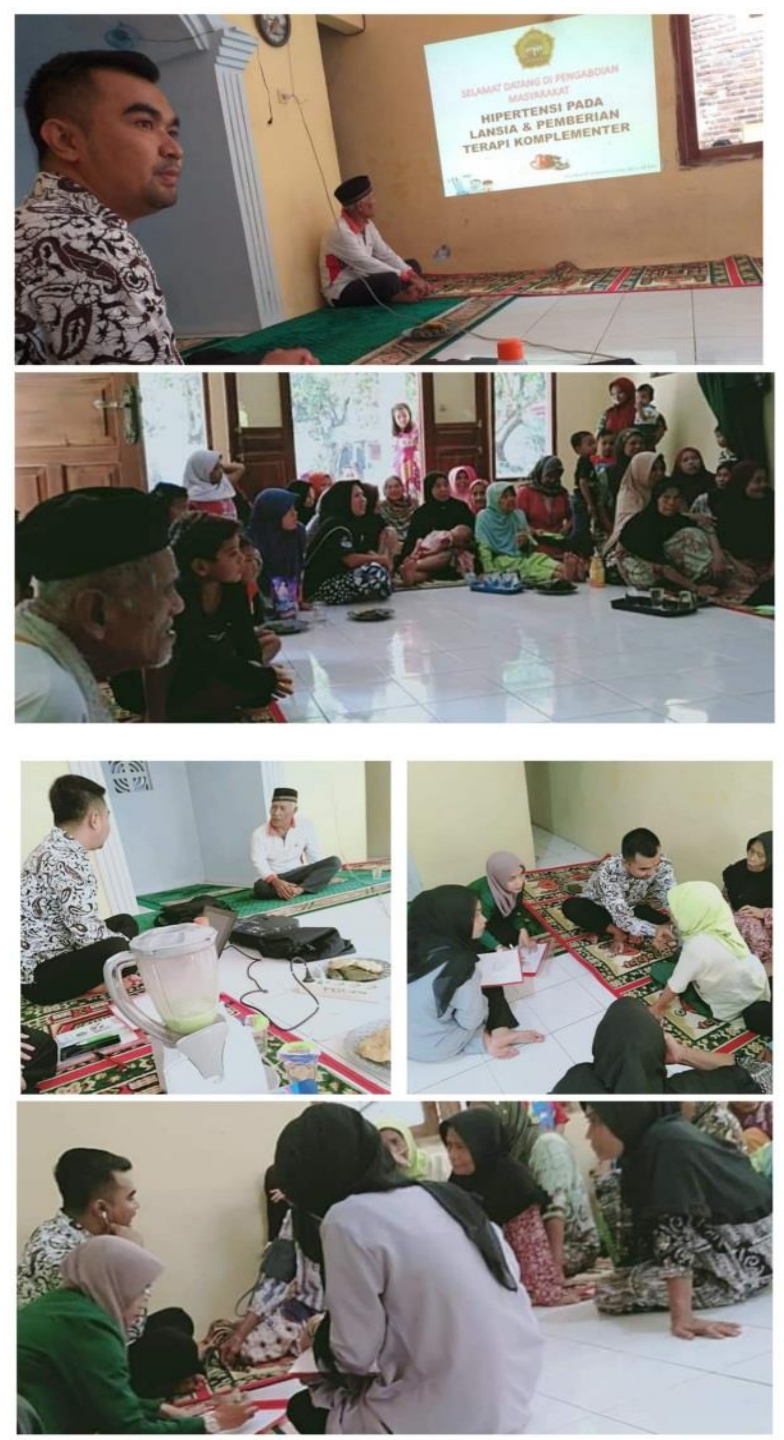

Gambar 1. Aktivitas Pengabdian Masyarakat

\section{SIMPULAN}

Intervensi yang sudah diterapkan dengan memberikan jus mentimun pada lansia penderita hipertensi memberikan keuntungan pada pemberian asuhan keperawatan pasien hipertensi. Metode pemberian jus mentimun berpengaruh terhadap penurunan tekanan darah pada pasien hipertensi. Ada berhasilnya pemberian jus mentimun, masyarakat Desa Kondangjaya 
63 Efektivitas Jus Mentimun Terhadap Penurunan Tekanan Darah pada Lansia Penderita Hipertensi di Desa Kondangjaya Pandeglang - Banten-Ucu Wandi Somantri

DOI: https://doi.org/10.31004/abdidas.v1i2.14

berkomitmen untuk merubah perilaku hidup sehat. Evaluasi dari kegiatan menunjukkan bahwa masyarakat Desa Kondangjaya sangat berpartisipasi, sangat peduli terhadap kesehatan dan sangat antusias dalam mengikuti kegiatan yang diadakan oleh petugas kesehatan maupun perangkat desa.

Kegiatan pengabdian masyarakat untuk menurunkan tekanan darah pada lansia di Desa Kondangjaya, Kabupaten Pandeglang berjalan dengan lancar. Jus mentimun bisa menurunkan tekanan darah dengan aturan minum $2 \mathrm{x}$ dalam sehari dengan waktu pemberian pagi dan sore, sedangkan jumlah yang diminumkan dalam 1 kali pemberian yaitu 1 gelas kurang lebih $250 \mathrm{cc}$.

\section{DAFTAR PUSTAKA}

Etri Yanti, Niken, D. A. (2018). PENGARUH PEMBERIAN JUS MENTIMUN (Cucumis sativus L) TERHADAP TEKANAN DARAH PADA PENDERITA HUPERTENSI. Jurnal Kesehatan Saintika Meditory Jurnal Kesehatan Saintika Meditory, 1(August), 79-88. http://jurnal.syedzasaintika.ac.id/index.php/ meditory/article/view/244

Ismalia, N., Zuraida, R., Lampung, U., Gizi, B. I., Kedokteran, F., \& Lampung, U. (2016). Efek Tomat ( Lycopersion esculentum Mill ) dalam Menurunkan Tekanan Darah Tinggi Effect Tomato ( Lycopersion esculentum Mill ) for Decreasing High Blood Pressure. Majority, 5(4), 107-111.
Pola Konsumsi Natrium dan Lemak sebagai Faktor Risiko Terjadinya Penyakit Hipertensi di Wilayah Kerja Puskesmas Kandangan Kecamatan Kandangan Kabupaten Hulu Sungai Selatan. Jurkessia, 5(4), 1-7.

Sumiati, N. (2017). Ketidakpatuhan Pola Makan pada Pasien Hipertensi di Kota Malang. Faculty of Health Sciene. Undergraduate (S1) Thesis. Universitas Muhammadiyah Malang. Malang: 29 November 2018. 9-42. 